\title{
The specificity and determinants of speech-language therapy with a patient after ischemic stroke. Case study
}

\section{KEYWORDS}

ischemic stroke, aphasia, speechtherapy proceedings

\begin{abstract}
Kaźmierczak Monika, Wichurska Karina, The specificity and determinants of speech-language therapy with a patient after ischemic stroke. Case study. Culture - Society Education no 2(16) 2019, Poznań 2019, pp. 133-147, Adam Mickiewicz University Press. ISSN 2300-0422. DOI 10.14746/kse.2019.16.9.
\end{abstract}

Patients with ischemic brain injury may be affected by damage of brain centers responsible for speech, which is the cause of aphasia. Because the disintegration of linguistic and communication skills makes it difficult or even impossible to communicate with the environment effectively, every patient with aphasia requires speech therapy. In diagnosing aphasia, a qualitative approach is desirable. Presented case proves that the main goal of reeducation of a patient who has lost the ability to communicate with the environment is first to restore this contact in the simplest form, and then gradually rebuild various types of competences and improve implementation, using adequate methods, techniques and tools. All activities, taking into account the possibilities and limitations of the patient and adapted to the dynamics of her speech disorder, were aimed at improving the quality of patient's life and becoming more independent, so that she could successfully participate in social life.

\section{Introduction}

Speech is not only the key to communication and learning, but also an important factor shaping personality. It is the product of human reason that shapes thinking.

\footnotetext{
${ }^{1}$ ORCID https://orcid.org/0000-0003-4396-3627.
} 
It is a really complex set of activities that engages all thought processes. Thanks to several insights and images in the cortex, information about sounds, feelings, names and mathematical activities is stored. Called at the right moment from the human knowledge and experience, they allow to identify the elements of the surrounding world, to become familiar with it (Lewicka, Stompel, Nowakowska-Kempna, 2014). Speech disorder associated with the disintegration of language and communication skills (Grabias, 2014) inhibits this process, and disorganization indicates the occurrence of a pathological change in the course of brain mechanisms, which ensured effective participation in the communication process - until the incident occurred. It should be borne in mind that the ability to process linguistic information affects other systems (cognitive, emotional, family, social), which are also destabilized during the disorder, and that jeopardizes the effectiveness of communication (Pąchalska, 2008; 2011).

Determining the cause of cerebrovascular disease is the basis for the development of an appropriate diagnostic and therapeutic plan by a speech therapist. It determines the choice of the appropriate procedure, the choice of treatment methods that the patient would be able to use, and the establishment of an individualized strategy for speech therapy. Language and communication disorders may have different severity and affect the general functioning of the patient to a different extent in case of ischemic stroke (ICD-10: 163-164), its topography and the size of the ischemic focal point, as well as general patient health before the incident.

If the areas of the brain responsible for speech are damaged during an ischemic stroke, the patients are diagnosed with aphasia, or „impairment” of individual language functions, resulting in disability in the communication with other people, which in turn leads to emergence of disability (handicap) caused by social isolation, loss of social roles, etc. (Pąchalska, 2011: 156). Although aphasia is only one of the symptoms of brain damage, language communication (in the aspect of locution and interaction) involves the largest brain resources, its complexity results in an extremely complex clinical picture. Polish researcher of speech mechanisms, Mariusz Maruszewski, showed that isolated forms of aphasia are extremely rare. Almost always a movement component is added to the sensory aphasia, and in the aphasia of motion there is also some impairment of understanding words (Sadowski, Chmurzyński, 1989).

\section{Principles and specification of logopedic proceeding in aphasia}

Aphasia is a symptom of brain damage that occurs in a man living in a social environment (Maruszewski, 1974) - this is a fact that requires special emphasis. The 
pre-existing affective patient had linguistic abilities adequate to his age, education, profession, social status, etc., but as a result of the disease, these abilities were lost or, to a greater or lesser extent, disrupted. In order to better understand the problems of a patient with aphasia and to develop effective therapeutic strategies, special attention should not be paid to the state but to the process, and thus to closely observe the patient's linguistic behavior at subsequent stages of the diagnostic and therapeutic process (Pąchalska, 2011).

For full diagnosis, three types of diagnoses should be used: location diagnosis using neuroimaging, functional diagnosis (containing the results of neuropsychological examination) and speech therapy diagnosis, which poses a question about deficits in the field of language and communication. The diagnosis of aphasia is difficult to separate from the therapy. Due to the unstable clinical picture of a patient with aphasia, each diagnosis has a working character and cannot be treated as a final judgment about the patient's condition. The multiple speech therapy assessment aims to verify earlier diagnostic hypotheses, prognostic positions and the therapeutic strategies. This is due to the variability of the image of linguistic disorders, resulting from the course of the disease, the possibility of compensating the brain, adaptation mechanisms of the patient, rehabilitation activities, clinical condition of the patient and his frame of mind (Panasiuk, 2015).

In the process of diagnosing a patient with aphasia there are two main tasks: identifying the actual patient's current problems, aimed at the proper targeting of rehabilitation efforts, and establishing a prognosis regarding the current and possibly - future level of the patient's functioning in terms of language behavior.

In the diagnosis of affective speech disorders, a speech therapist takes into account data from many sources: clinical documentation (diagnosis, neurological and instrumental results, previous pharmacological treatment and rehabilitation, hospitalizations, history of illness), obtained in an interview (with a patient and/or family, guardian, staff medical), based on observation (orientation, emotional state, communication and language interaction, clinical state dynamics), as well as the results of experimental and clinical trials, data from questionnaires or scales to assess language skills. The speech therapy diagnosis, concerning communication and language deficits, is a multi-stage one and covers various areas: building spoken word, speaking and understanding of spoken messages, written and iconic texts, building and receiving non-language text, reading, writing, drawing, counting also orientation, praxis and memory (Panasiuk, 2014; 2015; Pąchalska, 2008; 2011).

Importantly, the diagnosis of aphasia in „almost-acute” patient's condition is not recommended. A large part of the symptoms of speech disorders during this 
period results from the action of neurodynamic factors, for example from edema, cardiovascular disorders or reduction of metabolic enzymes (Panasiuk, 2015). After their resolution, some symptoms may be remitted and spontaneous improvement in language skills occurs.

All the strategies and the methods of therapeutic treatment in all cases of aphasia are dependent on several variables: the results of the speech therapy diagnosis, the clinical condition of the patient, the conditions under which the therapy is conducted and the period during which the patient can use it. There is a maximalist, minimalist and realistic strategy (Maruszewski, 1974, Nowakowska, 1978, Panasiuk, 2015). The last one is used when the anticipated period of therapy is insufficient to eliminate all deficits and there is a fear that after it expires, the patient may remain without professional care. Conducting therapy is then focused on making practiced skills as useful as possible in everyday communication.

In the therapy of patients with aphasia, indirect (stimulant) and direct methods are used. The first ones stimulate the patient to make attempts to communicate. Among them, breakdown methods are mentioned (it is assumed that the essence of speech disorders is the blocking of language functions, that is why it triggers automated verbal activity), stimulating (language activity of the patient is associated with the content of language material, therefore the choice of material depends on interests, personality traits and communication needs of a patient) and pre-emptive (aimed at preventing possible later psychogenic disorders, eg reluctance of the patient to make attempts to make verbal contact). The direct methods are based on an analytical approach in the diagnosis of aphasia: finding a basic defect, making a diagnosis, and then determining procedures appropriate for rebuilding language skills, by passing the damaged link of the functional system. They are used in cases when it is possible that the second hemisphere of the brain will take over the dysfunctional functions, or if there is a reserve capability for the given language activities (Panasiuk, 2015; Maruszewski, 1974).

In the case of aphasia, the speech therapy procedure is to stabilize the breakup, and sometimes to rebuild all types of competences and streamline the implementation (Grabias, 2014; Panasiuk, 2014). In the opinion of Maruszewski (1974) in a situation when, as a result of brain damage and growing adverse psychogenic changes, the patient lost the possibility of any contact with the environment, the main goal of re-education is to restore this contact in its simplest form. This is a prerequisite for further work with the patient.

In re-education, the first important step is to make the patient aware that the therapist whom he sees will be conducting exercises with him, and the second step- to obtain (after the therapist's appearance) positive emotional reactions. It 
is necessary to meet the patient systematically, but at the beginning without giving him any specific tasks, showing the auxiliary materials brought (eg pictures of everyday objects, pictures of family members, simple aids for construction tasks, etc.). Decomposing them, you should limit yourself to a gesture of paying attention to them and a moderate verbal commentary. In the case of causing the patient's interest in a category of subjects, one should focus in further contacts on this material. Other nonverbal constructional tasks (eg a pyramid of colored discs) are also useful, which help in getting a patient's cooperation and have a psychotherapeutic effect (the execution is very simple without many verbal explanations, gives the broadcaster a signal that he can understand the commands). The selection of tasks for the patient must meet two criteria: the possibility of explaining the principle without verbal explanations and accessibility for the patient.

After the initial stage, which should reinforce the patient's conviction about the possibility of cooperation and getting him to concentrate on the tasks, one should go to more specific activities. The patient's task is to learn how to focus on the content of the material being demonstrated, for example by means of two sets of identical images (a lotto task). The more difficult task will be to assign pictures that represent the same objects, but are drawn in a slightly different way, for example a round table and a rectangular table. Conducting classes in the same way, you can use specific objects, such as cutlery or playing cards. Hearing impulses are gradually introduced by exchanging names of objects, reproducing specific sounds for them or by saying simple sentences in relation to these objects. The patient begins to associate the auditory patterns (words and sentences) with the visual material.

This can be a transition to exercises consisting in making simple but verbal commands, eg a therapist says: „This is a dog”, „It is sleeping in a kennel," and then asks the patient to show „What barks?” etc. It is important to ask questions for individual pictures, but the answer is both verbal and gestational, eg "Does it give milk?" Thanks to this stage, the second important threshold in the reeducation of the patients with aphasia is exceeded - the verbal communication threshold, despite that in an elementary form. This is the time in which classes are initiated that are more focused on the specific difficulties of the patient, which concern his/ her understanding, expression, writing, reading, etc. The first attempts of verbal answers to the instructions directed to the patient are also possible. The described methods of work may change the character of speech disorders occurring in the patient, for instance - instead of total aphasia only partial disorders are observed.

The general principles of re-education of patients with aphasia are (Maruszewski, 1974): 
a) The principle of adapting the methods of re-education to the character of disorders occurring in a given patient;

b) The principle of re-education as early as possible;

c) The principle of using the patient's preserved abilities;

d) The principle of using the so-called additional aferentation and external assistance - if the patient is unable to properly receive and analyze stimuli from a given category (eg disorder at the level of visual perception, auditory or signals coming from the articulatory organs);

e) The principle of psychotherapeutic attitude and the principle of „success” the manner of behavior of a person who works with the patient, his patience and kindness significantly affects the success of reeducation. This principle should be implemented in an individualized way - for example, in the case of people who are excessively critical of their condition, too enthusiastic praise can be counterproductive;

f) The principle of stimulating and organizing the patient's activity - the patient should be made aware of the importance of his / her involvement in re-education, what are the reasons for his / her difficulties and indicate the correct ways of dealing with the new situation;

g) The principle of choosing the right material for re-education classes;

h) The principle of flexibility - in the assessment of the type and causes of the patient's difficulties and the choice of methods.

\section{Methodology of own research}

The schema of speech therapy research on people with suspected brain damage and aphasia requires taking into account data in the field of neurology, neuropsychology, speech therapy (neurologopedic) and linguistics, as well as social sciences. Neurological data relate to the pathomechanism and location of brain damage. They are associated with the organic and location diagnosis. Neuropsychological information includes assessment of the state of higher cognitive functions. Linguistic data determine the current state of language skills, while social ones - refer to the age, origin, gender, family situation and education of the patient. These factors interpenetrate, creating a „mosaic of often individualized images of pathology" (Panasiuk, 2015: 869), which is why a qualitative approach is important in diagnosing aphasia. Only then the choice of experimental and clinical trials enables a full analysis of speech activities and language behavior in both aspects: analytical and functional. The analytical aspect refers to language 
competences and skills, while functional aspect refers to competence and communication skills.

Used to diagnose speech disorders in a patient who has stabilized clinical symptoms, subsequent tests were to assess the state of competences and language and communication skills of the patient based on individual language behaviors (eg understanding, repeating, naming) and higher cognitive activities (eg memory, gnosis, praxis). Speech therapy in this approach is multi-stage, and its results allow to set up a speech therapy diagnosis - an indication of the type and depth of aphasia (Panasiuk, 2015).

\section{A case raport}

\section{General information}

A sixty-three-year-old patient, B. A., with visible speech disorders and right-sided hemiparesis, was admitted to the Care and Therapy Institute on February 1, 2016. The woman was previously hospitalized in the Stroke Department with Early Neurological Rehabilitation due to symptoms of ischemic stroke of the central nervous system in the form of muscle weakness on the right side and global aphasia.

The speech therapy and psychological support provided, allowing to observe the dynamics of changes in the functioning of the patient, lasted from February 2 to September 7, 2016. Meetings were held as many as three times a day, three to five times a week, depending on the patient's condition. The first session usually took place in the morning and lasted maximum 15 minutes - it was aimed at establishing contact with the patient, then included exercises to relieve, stimulate and stimulate to raise the motivation for rehabilitation. The second one was longer, lasting usually 45-60 minutes and was based on the inclusion of exercises directly disturbed activities. The last meeting usually took place in the afternoon and its main purpose was to familiarize the patient with the tasks she was supposed to do on her own for the next meeting.

The therapeutic treatment was determined by the state of the patient's linguistic and cognitive abilities. In addition to the formulation of the therapy program, activities for carers in the Institute and people from the closest environment were also developed. During the monthly meetings of the medical staff, the current state of functioning of the linguistic patient was presented and some advice, important in everyday communication with the patient, was given. A detailed description of disorders connecting with aphasia and indications to stimulate the activity of the patient during the visit was also prepared, but they were not used due to the lack of 
meetings with the only patient's close person (cohabitant). In addition, a periodic assessment of progress in improvement and control speech therapy was conducted. The diagnostic hypothesis was constantly verified and the therapy program was modified, adapting it to the patient's current communication and language behavior.

\section{Speech therapy diagnosis}

The methodology of therapeutic treatment in aphasia is guided by the principle: "The reorganization of impaired linguistic activities consists in breaking the basic defect, but always based on the preserved elements of the dynamic speech chain" (Panasiuk, 2015: 909). During the logopedic diagnosis of the patient B. A. ${ }^{1}$ as the first, after a few weeks after the stroke, the speech test was carried out with the SODA test (Scale Assessment of Aphasia Dynamics), which showed that the speech was completely abolished (score 1.5 points). After several months of therapy, the Test of naming by Antoni Balejka was carried out, during which the rate of speech was slightly accelerated due to the patient's great involvement. The understanding, speech prosody and breathing-phonation-articulation activities were preserved. Numerous paraphernalia, perseverations and substitutions of sounds have been noticed. At the suggestion of a syllable the patient usually ended the word correctly, the hint of the first sound did not always give a satisfactory result. The result of the Token Test (short version) confirmed great difficulty in understanding complex commands (97/163 points).

The Boston Test for Diagnosis of Aphasia (BTDA), conducted after almost half a year of therapy, showed a relatively good understanding of speech, especially differentiation of words, understanding of body part names and simple commands (II.A - 62.5/72 points, II.B - 15/20 points, II.C - 6/15 points, II.D - 3/12 points), global reading preservation: the patient identified letters and words, and was able to assign names to designate objects (IV.A - 8/10 points, IV.B - 2/8 points, IV.C $6 / 10$ points, IV.D - $3 / 30$ points, IV.E - 0/10 points, IV.F - 6/10 points), relatively preserved non-verbal oral efficiency and repetition of words during the study of oral expression (III.A.1 - 5/12 point, III.A. 2 - 1/14 point, III.B - 0/8 points. , III.C - 0/2, 0/2, 1/2 point, III.D - 6/10 points, III.E - 0/16 points, III.F - 0/30 points, III.G - 0/105, III.H - 0, the patient did not undertake the task) and writing in two aspects: writing technique and elementary dictation (VA - 11/21 points,

\footnotetext{
1 The logopedic diagnosis of the patient B. A. - see more in Dynamics of the image of speech disorders in a patient after ischemic stroke - case study (Kaźmierczak, Wichurska, 2018).
} 
V.C $-6 / 15$ points, the patient refused to perform the remaining tasks). The volume of speech, voice and speed were normal, the biggest difficulties the patient had with casual conversations and stories.

Therapeutic activities for the patient B. A. were designed based on the use of preserved functions (positive diagnosis). In this patient's case there were:

- preserved autopsychic and allopsychic orientation;

- awareness of own speech disorders and their manifestations;

- adjusted mood, emotions expressed correctly, motion in the norm;

- lack of disturbances of perception, content and thinking;

- performing most of simple commands;

- correct indication of objects (including unusual ones) in the pictures;

- correct confirmation / denial (checking by tucki's tests);

- the ability to read and understand words and simple sentences;

- possible copying of words, writing letters for dictation;

- correct time selection (test of drawing the clock);

- preserved abstract and conceptual thinking;

- preserved planning, analysis and visual-spatial synthesis;

- correct recognition of differences between objects;

- oral praxis preserved, usually correct;

- visual correctness (Poppelreuter Figures, incomplete letters).

Reeducation of the patient was mainly focused on building relationships, improving linguistic communication, also in the interactive aspect. The plan and the therapy program included (negative diagnosis):

- disturbed spontaneous speech;

- a significant problem with speech initiation;

- the current embol „no”;

- verbal and literal verbs;

- perseveration;

- disturbed automated speech;

- partially disturbed understanding of situational speech (in two-part orders the patient focuses on one part, omitting the other);

- disturbed understanding of inflectional and prepositional structures;

- self-distorted writing, errors in the form of paragrafhy even in the signature (hemiplegia of the right, dominant hand);

- disturbed arithmetic skills (errors even in elementary tasks such as adding individual digits in the range of up to 10);

- weak ideomotoric praxis (current perseverations in subsequent orders, during the diagnosis the patient showed only how the tea mixes); 
- partially disturbed dynamic praxis (skipped the middle element of the series, the patient skipped the clenched fist in the series);

- letters read incorrectly (aloud);

- failure to execute written orders.

During the first weeks after ischemic stroke, in the hospital, the patient was diagnosed with total aphasia. It was also maintained in the first two weeks after arriving at the Care and Treatment Department. Along with the stabilization of the patient's clinical condition, these symptoms were alleviated, then speech disorders took the form of mixed aphasia (with the predominance of motor aspect) of a significant degree. The state of language skills improved over time and links started to emerge within the dynamic functional system, which determined the specificity of the difficulty in speaking and understanding at subsequent stages of speech therapy. Eventually an image of a kinesthetic motoric aphasia (afferent, centripetal-motor) emerged, characterized by a violation of speech kinesthesia.

The disorder concerned somesthetic gnosis, i.e. the analysis and synthesis of sensory experiences from speech organs. The exploratory reaction of the articulatory apparatus was observed, and the implementation of separate speech sounds came to the patient with obvious difficulty. This defect caused difficulties in articulation - there were distortions of spoken words and sounds, voice paraphasies and - in analogy in the writing - letter paraphasy. All types of oral and written speech were disrupted - spontaneous, dialogical, monologue, repetition and naming as well as reading and writing. The patient, without feeling the motive of the word, was unable to write or read it. The understanding of the statement was disturbed secondarily, to a lesser extent, at a high level of logical-grammatical organization. Due to the disintegration of sensory patterns of consonants, there were secondary deficits in recognizing important features of speech sounds (phonematic hearing). The so-called an articulative act was damaged, which in turn led to difficulties in finding the right pattern of articulation when speaking the sound.

\section{The specificity of the diagnostic and therapeutic process with the patient $B$. A.}

The main goal of the long-term diagnosis and therapy was to understand the nature of speech disorders and deficits of other psychological functions, to determine the dynamics of disorders observed in the patient and to plan rehabilitation adapted to her needs. The objectives of speech therapy at individual stages were drawn 
up based on the methods of rebuilding speech in the aphasia of Lubow Siemionowna Cwietkowa (1985).

I. General verbal activation of the patient - preparation for speaking and transmitting intentions:

- creating psychological readiness for communication;

- preparation of the articulation apparatus and muscles participating in the speech act.

The essence of this stage was to divert attention from speech and focus on the operational operation - this leads to a real unblocking of the speech.

II. Rebuilding the ability to say separate words

III. Active use of developed words

IV. Rebuilding the skills of sound analysis of words

V. Developing the skills of articulating individual sounds

VI. Rebuilding the ability to construct a sentence and a developed statement, and the elimination of agramatism.

The high dynamics of the patient's aphatic disorders determined the continuous modification of the speech therapy program. When there were symptoms of total aphasia with alexia and agraphia (first stage of therapy) and sensory-motoric aphasia (the second stage of therapy), speech rehabilitation focused on improving the understanding of verbal messages in a situational context. Improving understanding of spoken and written texts influenced the improvement of efficiency in independent creation of verbal and - mainly - non-verbal messages. At subsequent stages of therapy, language deficits took on a more and more specific picture. The main goal of the therapy was to overcome the basic defect lying at their base through other, preserved links in the speech chain. At the last stage of the therapy with mixed aphasia emerged an image of motoric afferent aphasia (the third stage of therapy). At that time, the main goal was to overcome the disorders of the somesthetic gnosis.

The research and therapeutic situation was significantly hampered by many factors: first of all, the difficult family and social situation of the patient as well as the high reluctance and symptoms of aggression when trying to make contact with her. The patient was often depressed and apathetic due to the very rare visits of her partner. The initial stage of the speech therapist's meeting with the patient consisted in establishing warm and cordial contact. Relevant in this process was the accompanying and supporting the patient in everyday activities, i.e. help and conversation during breakfast or taking the patient to the therapy workshops and an attempt to integrate her with the group. This provided the opportunity to observe spontaneous verbal and non-verbal reactions of the patient and gradually introduce her into the therapeutic and diagnostic situation. 
At the initial stage, the patient's impact was particularly significant in the inhibitory, directly exercising, psychotherapeutic and forerun actions. These were intonation and rhythmic methods, emotional methods and methods stimulating memories. Such features as intonation, melody, rhythm and accent allow us to influence the intention of speech, prepare for it and "facilitate the flow of some meanings lying behind intonation" (Cwietkowa, 1985: 4). In addition, the meaning and sense of words and entire situations were revived using non-verbal methods. Games and plays were used here, i.e. domino (pictorial, letter, ordinary), lotto, puzzles. Items were classified according to a given feature, non-conforming elements were identified and all forms of construction activity were used. Work was also begun with the language text - automatic sequences were recited, partly together, partially alone. They were days of the week, numbers from 1 to 10 or names of months.

In the next stage, the semantic-auditory method was used (Cwietkowa, 1985). It was necessary to shift the attention of the patient from the articulating side of speech to auditory and semantic. The patient was tasked with grouping the objects due to their features, drawing the developed objects in various ways, playing the subject lotto. Elements of the optical-imitative method were also used, the aim of which is to rebuild separate sounds based on oral sound and control the position of articulatory organs in the mirror. It turned out to be a very important element in the patient's speech reeducation process. Then the words were not spoken, but their semantic context was given. The patient tried to find the appropriate drawing, which showed the designation of the word sought. In the vast majority of cases, she succeeded in, what means that the words were updated properly and you could go to work on the ability to say them. As a result, the general model of operation of the articulatory apparatus was unblocked, the verbal mechanism was activated, and a dictionary with a small lexical resource was built.

Then the sound analysis of the words was rebuilt. Rhythmic elements of the word were spoken and its structure was tapped. Exercises were started with words composed of two identical open syllables (mama, lala, tata, papa), followed by two-syllable words, in which the consonant remained the same, but the vowel (eg koki, lale, etc.) changed. Then, two-syllable words with a second closed syllable and three-letter words. They were supported by reading and writing in order to consolidate the knowledge of speech. In the further part of the therapy, all forms of work based on the preserved analyzers were actively used. Imitation of articulation poses (controlling lips and tongue movement) in the mirror was introduced. This was to associate a specific set of articulators with the given sound. There were also used diagrams showing the position of the lips, the language during the 
articulation of individual speech sounds. At this stage, it was important to develop positional variants of sounds. The patient was encouraged to use her own listening affection and control the correctness of the sounds she pronounced. With the consent of the patient some records of short verbal creations were, and then they were listened to together. It was observed that the respondent coped better with words when the speech therapist helped to initiate them. The phonetic hint (and the observation of lip movement and therapist's tongue) clearly increased the probability of the required word.

Next, the phrase repetition method was used, for which picture stories turned out to be helpful. First, the patient arranged the pictures in a specific order and then spoke with the speech therapist with individual words associated with them. The task was to answer questions formulated on the basis of a set of illustrations, and at the end repeat the phrases spoken by the researcher. They were recorded, read and composed of words written on separate pages, eg „The little girl is sitting at the table". Similarly, sentence sentences were used, from which also phrases were built. This was to eliminate agramatism. In the patient's therapy process, it was very important to focus her attention on the sound and semantic side of speech. This speech semantics was especially important here - to revive words, their object and articulation ideas.

During the therapy, problems with the reproduction of the articulatory pattern of the sounds were observed - the patient could not find both the place and the manner of articulation (disturbance of articulation kinesthesia). In addition, the dissociation between the sound and the meaning of the words became clear, that is why all the mistakes in giving the yes / no answer were being made. The patient gradually began to try to express the automated sequences with the help of the therapist and react vividly with mimics to the questions she had heard. The prosody of speech was preserved, the patient often responded with embol, but with a changed accent and intonation. After some time, there was an improvement in understanding. The patient performed all simple commands when they were supported by a gesture and she began to do them without support. Compound commands required multiple repetitions. The patient's global reading improved significantly - she was able to match the signatures (words and simple sentences) to the illustration adequately.

After several months of regular meetings, the patient's mental and emotional condition improved significantly. She began to treat the therapists with greater respect, she was cooperating more willingly and she even began to smile. More often she came into contact with other patients, but only when the contact was initiated by others. During speech therapy one could observe a tendency to outbursts of 
anger and crying, as well as a high fatigue of the patient. It was difficult to concentrate on the task, it happened that for no apparent reason she threw her writing instruments, manifesting that she wanted to finish the classes.

After receiving information that the leaving home of $\mathrm{B}$. A. was planned, the speech therapist equipped her with an individualized album of functional phrases that facilitate everyday communication.

\section{Summary}

During the seven-month speech therapy, the patient's picture and the mechanism of language disorders changed and evolved, and thus the assessment and diagnosis of speech therapy were subject to continuous verification. Difficulties with giving speech, understanding it, but also with writing and reading resulted in a serious dysfunction in the communication with other people, leading to the creation of a specific disability status. The fact of the limited communication possibilities of the patient with aphasia had a significant impact on her mental state. The initial state of language, communication and social skills was not a good one, but the situation in which not only a warm contact was established with the patient, but also the emerging involvement in the therapeutic process was observed, was a breakthrough. With time, the patient began to perform complex commands, and in spontaneous speech more and more words appeared. She attended occupational therapy workshops more willingly, she was initiating contacts with other patients, helping them and laughing with them.

\section{Bibliography}

Balejko A. (2005), Test nazywania. Diagnoza i terapia osób z zaburzeniami mowy, Białystok.

Cwietkowa L.S. (1985), Niejropsichołogiczieskaja reabilitacija bol'nych. Riecz i intielektualnaja diejatel'nost', Moskva.

Grabias S. (2014), Mowa i jej zaburzenia, [in:] S. Grabias, M. Kurkowski (eds.), Logopedia. Teoria zaburzeń mowy, Lublin, pp. 15-71.

International Statistical Classification of Diseases and Related Health Problems, ICD-10, vol. I (2009), World Health Organization.

Jastrzębowska G. (1998), Podstawy teorii i diagnozy logopedycznej, Opole.

Kaźmierczak M., Wichurska K. (2018), Dynamika obrazu zaburzeń mowy u pacjentki po udarze niedokrwiennym mózgu - opis przypadku, Otorynolaryngologia no. 2, pp. 72-79.

Knychalska-Zbierańska M. (2014), Afazja - złodziejka słów. Studium przypadku, Logopedia Silesiana 3, pp. 271-284. 
Lewicka T., Stompel D., Nowakowska-Kempna I. (2014), Zaburzenia językowe w chorobach neurodegeneracyjnych - aspekty diagnostyczne i terapeutyczne, Logopedia Silesiana 3, pp. 76-94.

Maruszewski M. (1974), Chory $z$ afazja i jego usprawnianie, Warszawa.

Nowakowska M. T. (ed.) (1978), Rehabilitacja chorych z afazja, Wrocław.

Panasiuk J. (2014), Afazja - typologia zaburzenia. Interpretacja afazji z perspektywy interakcyjnej, [in:] S. Grabias, M. Kurkowski (eds.), Logopedia. Teoria zaburzeń mowy, Lublin, pp. 569-621.

Panasiuk J. (2015), Postępowanie logopedyczne w przypadkach afazji, [in:] S. Grabias, J. Panasiuk, T. Woźniak (eds.), Logopedia. Standardy postępowania logopedycznego, Lublin, pp. 869-916.

Pąchalska M. (2005), Neuropsychologiczna diagnostyka afazji, [in:] E. Szeląg, I. Gałkowski, G. Jastrzebowska (eds.), Podstawy neurologopedii, Opole, pp. 750-845.

Pąchalska M. (2008), Rehabilitacja neuropsychologiczna, Lublin.

Pąchalska M. (2011), Patogeneza i neuropsychologiczna diagnostyka afazji, [in:] Ł. Domańska, A. Borkowska (eds.). Podstawy neuropsychologii klinicznej, Lublin, pp. 153-194.

Pohjasvaara T. at al. (1998), Clinical determinants of poststroke dementia, Stroke no. 29, pp. 75-81.

Raciborski F., Gujski M. (eds.) (2016), Udary mózgu - rosnący problem w starzejącym się społeczeństwie. Raport Instytutu Ochrony Zdrowia, Warszawa.

Ryglewicz D., Milewska D. (2004), Epidemiologia afazji u chorych z udarem mózgu, Udar Mózgu no. 2, pp. 65-70.

Sacco R.L., at al. (2013), An updated definition of stroke for the 21st century: a statement for healthcare professionals from the American Heart Association/American Stroke Association, Stroke nr 44, pp. 2064-2089.

Sadowski B., Chmurzyński J.A. (1989), Biologiczne mechanizmy zachowania, Warszawa.

Siminska J., at al. (2016), Udar niedokrwienny mózgu - postępowanie przedszpitalne i wczesnoszpitalne, Journal of Education, Health and Sport no. 8, pp. 439-453.

Tatemichi T.K., at al. (1994), Cognitive impairment after stroke: frequency, patterns, and relationship to functional abilities, Journal of Neurology, Neurosurgery, and Psychiatry no. 57, pp. 202-207.

Wade D.T. at al. (1986), Aphasia after stroke: natural history and associated deficits, Journal of Neurology, Neurosurgery, and Psychiatry no. 49, pp. 11-16.

Walsh K. (1997), Neuropsychologia kliniczna, Warszawa. 
